\title{
Study HTHP Sintered WC/Co Hardmetal
}

\author{
Meysam Mashhadikarimi ${ }^{*}$, Uilame Umbelino Gomes ${ }^{a}$, Michel Picanço Oliveira $^{b}$, Renan Da Silva \\ Guimarães $^{b}$, Marcello Filgueira ${ }^{b}$ \\ a Federal University of Rio Grande do Norte-UFRN, Lagoa Nova, 59072-970, Natal, RN, Brazil \\ ${ }^{b}$ Northern Fluminense State University - UENF, Pq. Califórnia, 28013-602, Campos dos Goytacazes, \\ RJ, Brazil
}

Received: Received: June 20, 2016; Revised: September 5, 2016; Accepted: November 20, 2016

\begin{abstract}
$\mathrm{WC} / \mathrm{Co}$ is widely used as cutting tools, because has a unique combination of high strength, hardness, toughness, and moderate stiffness, especially with fine grained WC and finely distributed cobalt. WC/ Co powder mixture sinters by different methods such as vacuum sintering, microwave sintering and SPS. High pressure high temperature (HPHT) sintering is a proposed method that can result in better distribution of cobalt and avoid undesirable phases by using high pressure, high temperature and very short sintering time. In this study, a powder mixture of WC- $10 \mathrm{wt} \%$ Co was sintered by HPHT at 1500 to $1900^{\circ} \mathrm{C}$ under a pressure of $7.7 \mathrm{GPa}$ for 2 minutes. Microstructural/structural analyses were performed by SEM/EDS. Hardness and compression test were also done to obtain the effect of sintering parameters. It was found that HPHT sintering method can be used to produce WC/Co hardmetal with low sintering time and high production rate. It was realized that increasing sintering temperature in HTHP sintering method results in increasing density but hardness and compression strength increase by increasing sintering temperature up to $1800^{\circ} \mathrm{C}$ and then decrease.
\end{abstract}

Keywords: Hardmetals, High pressure high temperature, HPHT, WC

\section{Introduction}

WC-Co cemented carbides are widely used as cutting, machining and rock drilling tools in due to their high hardness and strength, good fracture toughness and wear resistance over a wide range of temperatures ${ }^{1}$. In its simplest form the cemented carbide consists of WC as hard phase and Co as cementing binder phase due to its excellent wetting, adhesion and adequate mechanical properties, however, there are some reasons to substitute it with other metalic binder $^{2}$. The conventional production route is through powder metallurgy, where the main steps are: ball milling mixtures of WC and Co powder in proper media; drying, pressing, debinding and liquid phase sintering in the temperature range $1400-1500{ }^{\circ} \mathrm{C}^{3,4}$.

Drifting Co between parts of carbide particles has an important rule during the sintering and can affect on gradient of cobalt content and make inhomogeneous properties in produced cemented carbides. Co drifts between parts of carbide were reported in literature with respect to the possibility of fabrication of functionally graded cemented carbides ${ }^{5-8}$.

WC grain growth is a common problem in sintering cemented carbide that can affect the mechanical properties. It were studied in various works some including carbides as grain growth inhibitors to suppress the growth ${ }^{9-12}$. During sintering the average carbide grain size increases by means of coarsening or Ostwald ripening, i.e. large grains grow

* e-mail: maysammkarimi@gmail.com and small grains dissolve, leading to an increase in average grain size. Abnormal grain growth may also occur, i.e. a few large grains consume all small grains, leading to an abnormally large grain size. In cemented carbides, where normal WC grain size is of the order of $\mu \mathrm{m}$ or less, abnormal grain growth can sometimes lead to grain sizes of several hundred $\mu \mathrm{m}$. In the case of cemented carbides the diffusion distances are very short and the common faceted shape of the WC particles indicates that the difficulty in forming new atomic layers rather than long-range diffusion is the rate controlling mechanism ${ }^{13}$.

In the present work, a WC/Co powder mixture prepared and sintered via high pressure high temperature sintering method at higher temperature than conventional sintering method. High pressure and high temperature allow decreasing sintering time to avoid WC grain growth, increasing production rate and improving some properties such as achieving to $100 \%$ relative density.

\section{Experimental procedure}

\subsection{Preparation and sintering of powders}

Commercial Co powder and WC powders were used as the starting materials. WC powder had an average particle size of $12.8 \mu \mathrm{m}$ and Co powder had an average particle size of $11.45 \mu \mathrm{m}$. Figure 1 shows corresponding morphologies of powders. Co and WC powders were weighted with the 


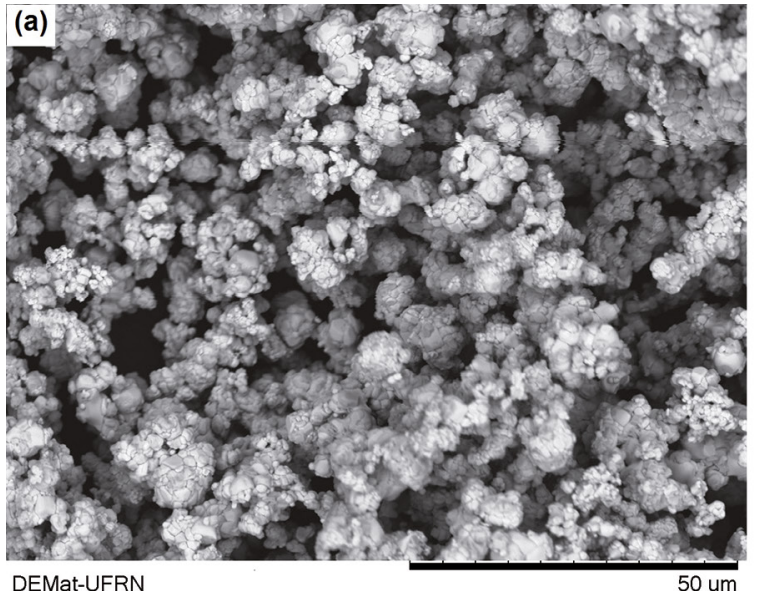

DEMat-UFRN

50 um

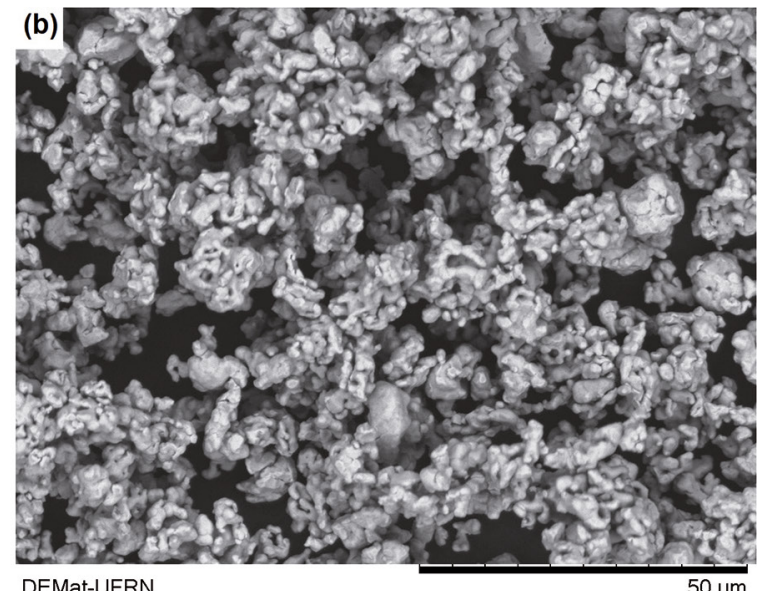

DEMat-UFRN

Figure 1: SEM morphologies of as-received powders. (a) WC and (b) Co.

nominal composition of WC-10Co powder, and mixed via ball milling in cychlohexane media. Milling speed and time were $200 \mathrm{rpm}$ and 2 hours respectively. The ball to powder ratio was 10 to 1 and hardmetal balls and vessel were used to prepare the powders. Finally, WC-10Co ball milled powder mixture was obtained after drying under vacuum. Figure 2 shows SEM photograph of mixed powder.

Prepared powder then capsulated in a cylindrical graphite capsule with $5 \mathrm{~mm}$ in diameter and closed with graphite cap. Sintering was done using an industrial high pressure high temperature (HPHT) machine. To study the effect of sintering temperature and morphology evaluation, compacted capsule were subjected to 5 different temperatures of 1500,1600 , 1700,1800 and $1900^{\circ} \mathrm{C}$. Sintering machine parameters lined up to apply $7.7 \mathrm{GPa}$ pressure for 2 minutes and heating was applied when the pressure reached to $7.7 \mathrm{GPa}$.

\subsection{Material characterizations}

The morphologies of WC, Co and WC - 10Co powders and sintered samples were discerned by a scanning electron microscope (Hitachi Tm3000 desktop SEM). The samples were ultrasonically cleaned for 30 minutes and then were sectioned, ground, and polished. Microstructures were observed in the mode of backscattered electron. The densities of sintered composites were measured by the Archimedes method according to ASTM B962. Hardness was measured with a $10 \mathrm{kgf}$ load according to ISO 3878 . Compression test was also done according to ISO 4506 in order to find the yield strength and compression strength.

\section{Results and Discussion}

Figure 3 shows the micrograph of sintered samples in different temperature. As it was found in SEM images, the samples sintered at $1500{ }^{\circ} \mathrm{C}$ had some porosities (Figure

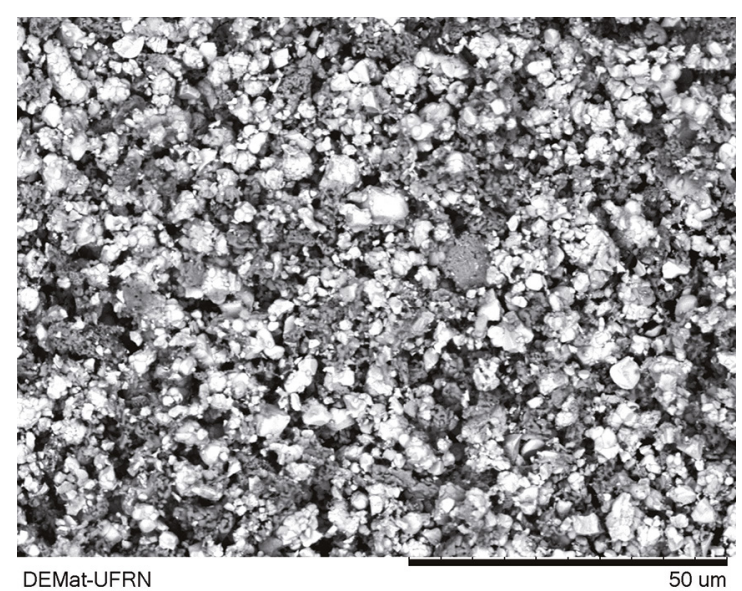

Figure 2: SEM morphologies of WC-10 Co powders.

3-a). Other samples were almost free of porosity however some small porosity also found in the samples sintered at $1600{ }^{\circ} \mathrm{C}$ (Figure 3-b). It seems that short sintering time at lower temperature even at high pressure is not enough to rearrangement the powder particle and diminishes the free space between particles. The binder (Co) acts as a viscous mass spreading over WC surfaces giving rise to Laplace forces and rearrangement of the carbide particles into clusters. The first stage of WC-Co sintering is limited by the rate of binder spreading, which in turn is governed by intrinsic properties of the binder and the microscopic character of the carbide-binder composite ${ }^{14}$. At low temperature, spreading of liquid Co between WC particles is slower in compared with higher temperature because of lower viscosity. In the diffusion point of view, at lower temperature the diffusion rate is lower than higher temperature, then, the rearrangement and solving the porosity during sintering is easier at higher temperature especially at very short sintering time. For these two reasons the higher porosity in samples sintered at lower temperature can be explained. 

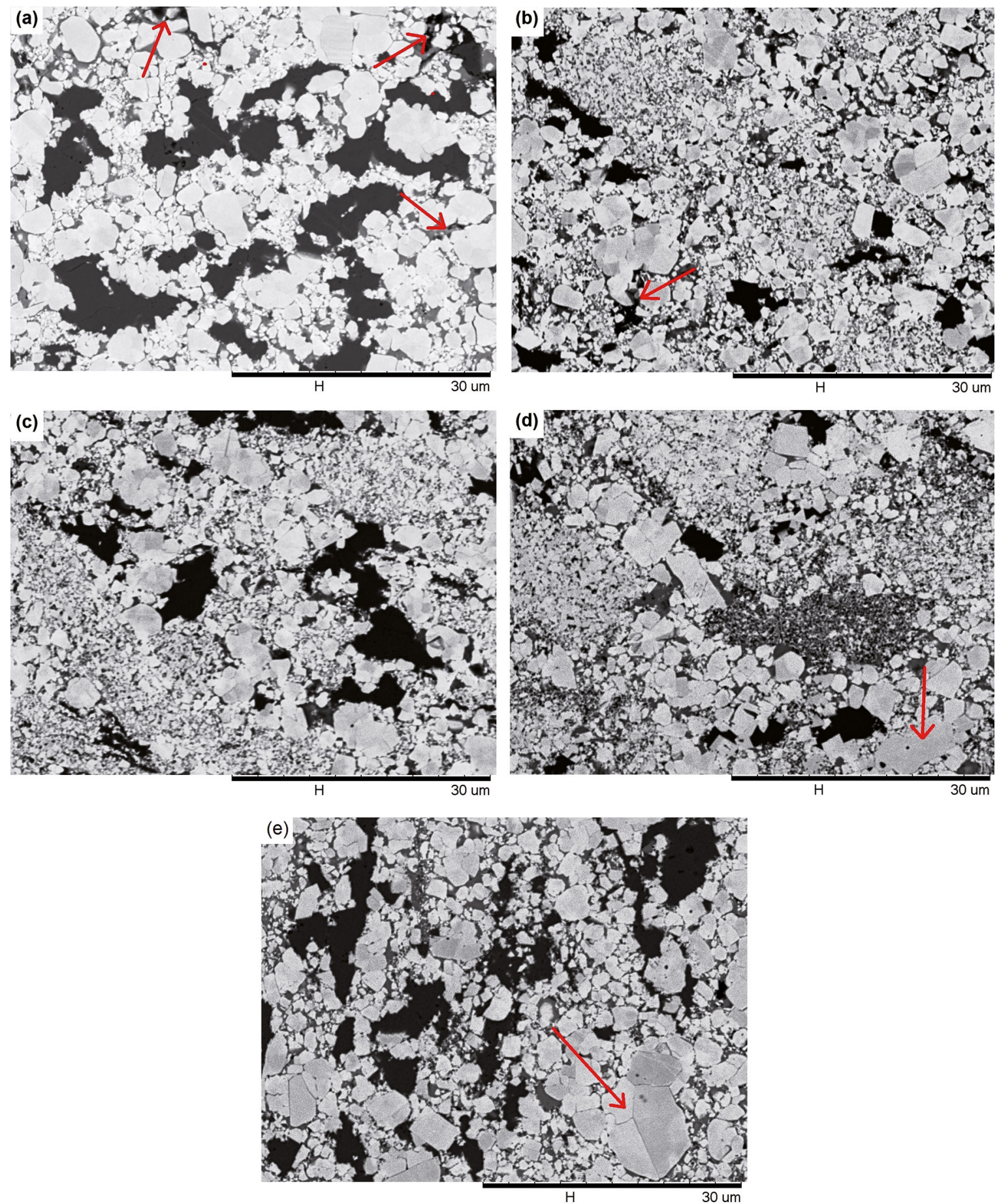

Figure 3: SEM metallographic images of sintered WC-10Co at different temperature. $1500^{\circ} \mathrm{C}$ (a), $1600^{\circ} \mathrm{C}(\mathrm{b}), 1700^{\circ} \mathrm{C}(\mathrm{c}), 1800^{\circ} \mathrm{C}(\mathrm{d})$, and $1900{ }^{\circ} \mathrm{C}(\mathrm{e})$. Porosity in lower temperature and abnormal grain growth in higher temperature.

Figure 3 also shows that the WC particle size distribution in all samples are almost the same specially for samples sintered at 1500 to $1700^{\circ} \mathrm{C}$ (Figure 3-a to 3-c). As it observed in samples sintered at 1800 and $1900{ }^{\circ} \mathrm{C}$, there is some abnormal grain growth in microstructure. It is clearer in samples sintered at $1900^{\circ} \mathrm{C}$ (Figure 3-d). It can be explained by the effect of higher temperature on diffusion rate. At higher temperature, because of the higher diffusion rate, it is easier for bigger particles to dissolve the smaller one and grows. Because of the short sintering time, these abnormal growths were found only in samples sintered at $1900{ }^{\circ} \mathrm{C}$ however some evidence of starting the growth in samples sintered at 
Table 1: Relative density of sintered sample at different sintering temperatures.

\begin{tabular}{lccccc}
\hline Sintering temperature $\left({ }^{\circ} \mathrm{C}\right)$ & 1500 & 1600 & 1700 & 1800 & 1900 \\
\hline Relative density $(\%)$ & $90-93$ & $93-97$ & 100 & 100 & 100 \\
\hline
\end{tabular}

$1800^{\circ} \mathrm{C}$ was also found but it seems that the sintering time was not sufficient for severe growth.

Table 1 shows the relative density of sintered samples to the theoretical density of WC-10Co at different sintering temperatures. The results are in agreement with the microstructure observation, as the samples sintered at $1500^{\circ} \mathrm{C}$ and $1600^{\circ} \mathrm{C}$ with some porosities (Figure 3-a and 3-b), did not achieve to the full density. All other three samples with no evidence of porosity (Figure 3-c to 3-e), have full density. As discussed before, achieving to the full density at higher temperatures can be related to higher diffusion rate at higher temperature. Also, as the temperature increases, porosities decreasing due to the higher liquid phase transaction during sintering could be a reason for increasing relative density ${ }^{15}$.

The variation of Vickers hardness with sintering temperature is shown in Figure 4. The hardness of WC-10Co hardmetals was sensitively dependent on the sintering temperature. As can be seen in Figure 4, the hardness increases sharply by increasing the sintering temperature from 1500 to $1700^{\circ} \mathrm{C}$ and then increases slightly by increasing temperature up to $1800{ }^{\circ} \mathrm{C}$. After $1800{ }^{\circ} \mathrm{C}$, increasing sintering temperature causes a notable decrease in hardness.

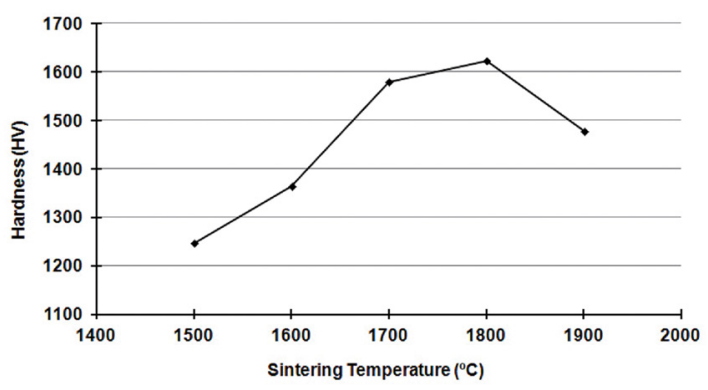

Figure 4: Vickers hardness as a function of sintering temperature.

Several studies reported hardness values for WC-Co hardmetals produced with different sintering methods. some of result listed in Table 2. As can be found, our results are in agreement with previous studies. Generally, hardness of the cemented carbides is affected by different parameters such as amount and type of the binder, size, distribution and the contiguity of the carbide phase, and porosity ${ }^{15}$. So, the rapid increase of hardness above $1500{ }^{\circ} \mathrm{C}$ seems to occur due to the formation of a liquid phase during sintering which leads to sharply increase the relative density and decrease in porosity. Moreover, the hardness slightly decreases above 1800 ${ }^{\circ} \mathrm{C}$. It can be attributed to the fact that the sintered density reaches the saturated value, and the crystallite size of WC considerably increases at temperatures above as showed in Figure 3-d and 3-e for samples sintered at 1800 and $1900{ }^{\circ} \mathrm{C}$.

Figure 5 and 6 shows the effect of sintering temperature on yield strength and compressive strength respectively. Result values are all in same order of magnitude with result obtained by Santos ${ }^{20}$ study of the mechanical properties of nanostructured WC-10Co hard metal, with and without grain growth inhibitors ( $\mathrm{VC}$ and $\mathrm{Cr} 3 \mathrm{C} 2$ ).

The trend in both graphs is almost the same as hardness results and the same explanation can be applied here as well. According to hardness and compression test results, it seems that the sintered density reached to saturated value at sintering temperature equal to $1700^{\circ} \mathrm{C}$ and after this temperature the WC particle size starts to grow that can have some effect on mechanical properties such as hardness and compression strength. This result is completely In compliance with the results achieved from density measurement (Table 1 and Figure 3).

\section{Conclusion}

The following conclusions have been drawn from the study of high pressure high temperature sintering of WC10Co cemented carbide:

1. HPHT sintering method can be successfully used in order to sinter cemented carbide with a high production rate.

2. Increasing sintering temperature up to $1900{ }^{\circ} \mathrm{C}$ via HPHT sintering makes it possible to decrease sintering time to 2 minutes.

3. Increasing sintering temperature causes in increasing relative density and to reach the $100 \%$ of relative density at $1700{ }^{\circ} \mathrm{C}$.

4. Hardness, yield strength and compressive strength increase by increasing sintering temperature up to 1800 ${ }^{\circ} \mathrm{C}$ and then decrease. The increase at first part is related to improving sintering phenomenon by increasing temperature and the decrease in second part is related to $\mathrm{WC}$ particles growth at high sintering temperature.

\section{Acknowledgment}

The authors gratefully acknowledge the support of Coordination for the Improvement of Higher Education Personnel (CAPES), Post Graduate Program in Material Science and engineering (PPGCEM), National Counsel of Technological and Scientific Development (CNPq), Ceramics Materials and Special Metals Laboratory (LMCME) in Federal university of Rio Grande do Norte (UFRN), and Advanced Materials Laboratory (lamav) in Northern Fluminense State University (UENF). 
Table 2: Comparison of hardness obtained with different techniques.

\begin{tabular}{|c|c|c|c|c|c|}
\hline Reference & Composition & Sintering method & $\begin{array}{c}\text { Hardness (kgf/ } \\
\left.\mathrm{mm}^{2}\right)\end{array}$ & $\begin{array}{c}\text { Sintering } \\
\text { temperature }\left({ }^{\circ} \mathrm{C}\right)\end{array}$ & Holding time (min.) \\
\hline [2] & WC-9.7Ni-0.3Al & CLPS & $1064-1100$ & 1460 & 60 \\
\hline [2] & WC-9.5Ni-0.5Al & CLPS & $1263-1297$ & 1460 & 60 \\
\hline [2] & WC-9.3Ni-0.7Al & CLPS & $1376-1424$ & 1460 & 60 \\
\hline [16] & WC-10Co-0.7VC & CLPS & 1610 & 1370 & 60 \\
\hline [16] & WC-10Co-0.7VC & CLPS & 1610 & 1410 & 60 \\
\hline [16] & WC-10Co & CLPS & 1310 & 1370 & 60 \\
\hline [16] & WC-10Co & CLPS & 1410 & 1410 & 60 \\
\hline [17] & WC-11Co & CLPS & 1782 & $1390-1470$ & - \\
\hline [17] & WC-17Co & CLPS & 1591 & $1390-1470$ & - \\
\hline [17] & WC-21Co & CLPS & 1483 & $1390-1470$ & - \\
\hline [17] & WC-12Co & CLPS & 1748 & $1390-1470$ & - \\
\hline [17] & WC-20Co & CLPS & 1359 & $1390-1470$ & - \\
\hline [17] & WC-14Co & CLPS & 1426 & $1390-1470$ & - \\
\hline [17] & WC-17Co & CLPS & 1335 & $1390-1470$ & - \\
\hline [17] & WC-21Co & CLPS & 1264 & $1390-1470$ & - \\
\hline [17] & WC-13Co & CLPS & 1395 & $1390-1470$ & - \\
\hline [18] & WC-12Co-0.4VC & HIP & $1340-1381$ & 1390 & 60 \\
\hline [18] & WC-10Co-2VC & HIP & 1430 & 1260 & 30 \\
\hline [19] & WC-20Co & CLPS & 1582 & 1350 & 1 \\
\hline [19] & WC-20Co-2.5VC & CLPS & 1693 & 1350 & 1 \\
\hline$[19]$ & WC-20Co-5VC & CLPS & 1709 & 1350 & 1 \\
\hline [19] & WC-20Co-7.5VC & CLPS & 1870 & 1350 & 1 \\
\hline$[19]$ & WC-20Co & CLPS & 1566 & 1400 & 1 \\
\hline [19] & WC-20Co-2.5VC & CLPS & 1701 & 1400 & 1 \\
\hline [19] & WC-20Co-5VC & CLPS & 1649 & 1400 & 1 \\
\hline [19] & WC-20Co-7.5VC & CLPS & 1687 & 1400 & 1 \\
\hline
\end{tabular}

CLPS - Conventional liquid phase sintering, HIP - Hot iso-static pressing.

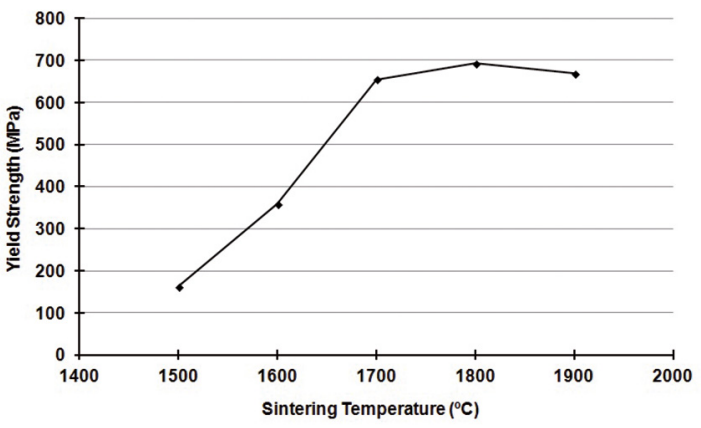

Figure 5: Yield Strength as a function of sintering temperature.

\section{References}

1. Su W, Huang Z, Ren X, Chen H, Ruan J. Investigation on morphology evolution of coarse grained WC-6Co cemented carbides fabricated by ball milling route and hydrogen reduction route. International Journal of Refractory Metals and Hard Materials. 2016;56:110-117.

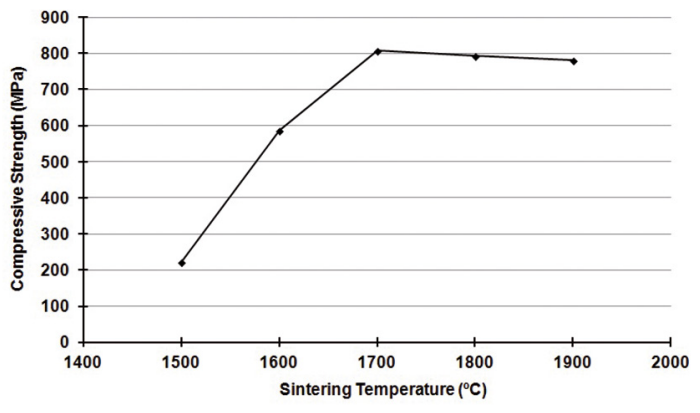

Figure 6: Compressive strength as a function of sintering temperature.

2. Correa EO, Santos JN, Klein A. Microstructure and mechanical properties of WC-Ni-Al cemented carbides for engineering applications. International Journal of Materials Research. 2011;102(11):1369-1373.

3. Su W, Sun Y, Wang H, Zhang X, Ruan J. Preparation and sintering of WC-Co composite powders for coarse grained WC-8Co hardmetals. International Journal of Refractory Metals and Hard Materials. 2014;45:80-85. 
4. Petersson A, Ågren J. Constitutive behavior of WC-Co materials with different grain size sintered under load. Acta Materialia. 2004;52(7):1847-1858.

5. Konyashin I, Hlawatschek S, Ries B, Mazilkin A. Co drifts between cemented carbides having various WC grain sizes. Materials Letters. 2016;167:270-273.

6. Eso O, Fang Z, Griffo A. Liquid phases sintering of functionally graded WC-Co composites. International Journal of Refractory Metals and Hard Materials. 2005;23(4-6):233-241.

7. Liu Y, Wang H, Yang J, Huang B, Long Z. Formation mechanism of cobalt-gradient structure in WC-Co hard alloy. Journal of Materials Science. 2004;39(13):4397-4399.

8. Eso O, Fang ZZ, Griffo A. Kinetics of cobalt gradient formation during the liquid phase sintering of functionally graded WC-Co. International Journal of Refractory Metals and Hard Materials. 2007;25(4):286-292.

9. Yoon BK, Lee BA, Kang SL. Growth behavior of rounded (Ti,W) $\mathrm{C}$ and faceted WC grains in a Co matrix during liquid phase sintering. Acta Materialia. 2005;53(17):4677-4685.

10. Sommer M, Schubert WD, Zobetz E, Warbichler P. On the formation of very large WC crystals during sintering of ultrafine WC-Co alloys. International Journal of Refractory Metals and Hard Materials. 2002;20(1):41-50.

11. Olson JM, Makhlouf MM. Grain growth at the free surface of WC-Co materials. Journal of Materials Science. 2001;36(12):3027-3033.

12. Huang SG, Liu RL, Li L, van der Biest O, Vleugels J. NbC as grain growth inhibitor and carbide in WC-Co hardmetals. International Journal of Refractory Metals and Hard Materials. 2008;26(5):389-395.
13. Mannesson K, Jeppsson J, Borgenstam A, Ågren J. Carbide grain growth in cemented carbides. Acta Materialia. 2011;59(5):1912 1923.

14. Petersson A, Ågren J. Rearrangement and pore size evolution during WC-Co sintering below the eutectic temperature. Acta Materialia. 2005;53(6):1673-1683.

15. Karbasi M, Karbasi M, Saidi A, Fathi MH. The Effect of Sintering Temperature on Microstructure and Hardness of the Milled WC- 20 Wt.\% Equiatomic (Fe,Co) Cemented Carbides. Journal of Advanced Materials and Processing. 2015;3(1):29-38.

16. Mahmoodan M, Aliakbarzadeh H, Shahri F. Effect of $\mathrm{Cr}_{3} \mathrm{C}_{2}$ and $\mathrm{VC}$ on the mechanical and structural properties of sintered WC-\%10wt Co nano powders. World Journal of Nano Science and Engineering. 2013;3(2):35-39.

17. Sheikh S, M'Saoubi R, Flasar P, Schwind M, Persson T, Yang J, et al. Fracture toughness of cemented carbides: Testing method and microstructural effects. International Journal of Refractory Metals and Hard Materials. 2015;49:153-160.

18. Soleimanpour AM, Abachi P, Simchi A. Microstructure and mechanical properties of WC-10Co cemented carbide containing $\mathrm{VC}$ or $(\mathrm{Ta}, \mathrm{Nb}) \mathrm{C}$ and fracture toughness evaluation using different models. International Journal of Refractory Metals and Hard Materials. 2012;31:141-146.

19. Kumar D, Singh K. High hardness-high toughness WC-20Co nanocomposites: Effect of VC variation and sintering temperature. Materials Science and Engineering: A. 2016;663:21-28.

20. Santos CM. The influence of grain growth inhibitor on mechanical properties of nano structured $\mathrm{WC} / 10 \mathrm{wt} \% \mathrm{Co}$. [Dissertation] Campos dos Goytacazes: Northern Fluminense State University, Material Science and Engineering, Post Graduate Program; 2011. 